\title{
MOVIMIENTOS POBLACIONALES EN EL CHACO SANTAFESINO. UNA VISIÓN DESDE LA ARQUEOLOGÍA
}

\section{Carlos N. Ceruti}

\section{Introducción}

Las tierras bajas del centro y norte de la Provincia de Santa Fe tienen dos grandes ambientes poblados desde al menos 2000 años a.p.: la cuenca del Salado-Bajos Submeridionales-Paleocauce Paranaense, ocupado por el espinal (Cabrera) o monte periestépico de Frenguelli, y la faja ribereña y llanura aluvial del Paraná, que da sustento al ecosistema del Paraná Medio.

En esta comunicación nos ocuparemos únicamente del primero. La mayoría de los sitios arqueológicos del Paraná Medio están vinculados a lo que denominamos entidad cultural Goya-Malabrigo, incluida por J. Rodríguez en su Tradición Ribereña Paranaense. Hay gran cantidad de material extraído en las últimas décadas que permanece inédito o que fue publicado en forma parcial (Campos 2004, Cornero 1999, Cornero y Puche 1995, Echegoy 1993 y 1994, Kurc y Carrara 2001, Lafon 1971). Nuestra opinión al respecto está expresada, entre otros trabajos, en (Ceruti 2003, Nóbile et al 1999 y Schmitz et al 1972).

\section{Los cazadores-recolectores del Holoceno tardío}

Las evidencias conocidas de poblaciones humanas antiguas en el centro y norte de la provincia de Santa Fe se ubican en el amplio triángulo que tiene como vértice inferior la desembocadura del Río Salado en la ciudad de Santo Tomé, y que incluye:

1. el cauce actual del Salado y la depresión recorrida por sus afluentes de la margen derecha;

2. el paleocauce del Paraná, ocupado por el sistema de los Saladillos- laguna Setúbal o de Guadalupe;

3. los afluentes que llegan a éste por la margen norte, como los arroyos El Toba y Malabrigo.

No conocemos qué ocurre en el Departamento 9 de Julio al norte de la depresión del Salado, en el Departamento Vera más allá de Margarita y la Laguna del Palmar, y ni en el Departamento General Obligado al norte de la ciudad de Reconquista. Teniendo en cuenta los hallazgos recientes en Charata, Campo del Cielo y otras localidades del Chaco (Salceda y Calandra 2003), es posible que exista una continuidad en el tipo de yacimientos, pero la falta de investigaciones -aunque sea n exploratorias-, transforman esa enorme área de $36.000 \mathrm{~km}^{2}$, casi la tercer parte de la Provincia de Santa Fe, en una "terra incognita".

El río Salado, cuyo abanico aluvial comenzó a formarse en el Terciario, penetra en Santa Fe cortando la Falla Tostado-Selva, que marca el borde este de la Laguna Mar Chiquita. Hasta llegar al centro de la provincia sigue la pendiente general del terreno con dirección 
noroeste-sureste y presenta numerosos paleocauces que indican su carácter divagante. Estas migraciones no se realizaron por deriva lateral ni por taponamiento de cauces, sino por fenómenos de avulsión, en los que el río, en una creciente importante, abandonó tramos de varios kilómetros de longitud tomando por una pendiente más favorable (Castellanos 1968, Iriondo 1983,1985, 1987, 2000).

Fenómenos semejantes fueron observados en épocas históricas $(1655,1703,1778)$ obligando a las autoridades españolas a realizar trabajos de rectificación del cauce para devolver el agua a las poblaciones ribereñas (Serrano 1938, Furlong 1955, Roverano 1983).

Al llegar al Paleocauce Golondrinas-Calchaquí, de origen tectónico, el Salado se encauza y tuerce el rumbo hacia el sur, desembocando finalmente en el Paraná. Estas dos fracturas longitudinales de primer orden (la falla Tostado-Selva y la falla del GolondrinasCalchaquí) están atravesadas por fracturas transversales de segundo orden, de dirección este-oeste. La más importante está recorrida parcialmente por el arroyo. Las Conchas, que confluye con el Salado y el Calchaquí en un paraje denominado "Las Juntas". En las proximidades existe una gran laguna triangular de origen tectónico, muy profunda (más de $5 \mathrm{~m}$ ) denominada La Blanca, al sur de la cual se extiende una amplia zona de divagación de meandros. En este punto, donde el Salado duplica su caudal, terminaron los intentos realizados en el siglo XIX por trazar una ruta navegable que uniera Santa Fe con Santiago del Estero (Rams y Rubert 1969).

Entre el arroyo Las Conchas y el San Antonio, ubicado al sur, en un área ocupada por paleocauces sepultados, se encuentran cuatro lagunas redondeadas, de origen tectónico y con un diámetro de alrededor de $5 \mathrm{~km}$ (lag. La Cabral, Palos Negros, La Verde y El Dentudo), y numerosas lagunas menores, originadas en hoyas de deflación.

El paleocauce del Paraná, en el otro extremo de la provincia, es una antigua llanura aluvial abandonada por el Paraná a fines del Pleistoceno o a comienzos del Holoceno. Se extiende entre Romang-Alejandra y la ciudad de Santa Fe, con $200 \mathrm{~km}$ de longitud y 35 a $40 \mathrm{~km}$ de ancho. En algunos tramos presenta diseño meándrico y en otros anastomosado, con paleocauces individuales de distinto tamaño formados por el cauce principal o por los brazos secundarios (Ceruti e Iriondo 1980, Iriondo 1984, 1985). Antes que el Paraná la abandonara, esta faja sufrió procesos de basculamiento de origen tectónico, indicados por la orientación noreste-suroeste de los paleocauces meándricos secundarios. "Una de estas fracturas ha desplazado lateralmente al paleocauce anastomosado unos $10 \mathrm{~km}$ en las cercanías de La Criolla. Merece destacarse la magnitud de este movimiento, teniendo en cuenta su edad extremadamente joven" (Iriondo 1985: 619). El borde elevado de la fractura está indicado por varias lagunas, la más importante de las cuales es La Brava.

En la actualidad, el antiguo valle aluvial está recorrido por los arroyos Saladillo Dulce y Saladillo Amargo, que comunican una larga serie de lagunas de poca profundidad (1 a 2 m), la primera y más importante la Laguna de Cristal. A la altura de las localidades de Naré-Helvecia, los dos cursos se unen para formar el Saladillo, que desemboca finalmente en el complejo lagunar Capón-Leyes-Setúbal. 
En todo este complejo paisaje, los elementos geomorfológicos de origen fluvial están parcialmente enmascarados por rasgos eólicos originados durante el último período árido del Holoceno superior. El suelo que se había formado sobre el loess pleistocénico (Formación Tezanos Pinto) fue erosionado y depositado en los interfluvios en forma de manto, cubriendo el relieve eólico preexistente y originando lo que Iriondo denomina Formación San Guillermo.

Este autor define a San Guillermo como "...un depósito de limo grueso a arena muy fina, de pocos decímetros hasta un metro de espesor, de color gris, textura migajosa y abundantes poros y canalículos. Se ha depositado cubriendo uniformemente el relieve anterior, incluso en los amplios ambientes pantanosos del Chaco y norte de Santa Fe. El espesor disminuye en general de oeste a este. En todos lados se encuentra parcialmente edafizada, con enriquecimiento en materia orgánica y otros procesos pedogenéticos asociados, resultado de las condiciones climáticas actuales" (1985: 162). Esta formación rellenó los cauces secos o semisecos, y al caer en las áreas lacustres deprimidas las transformó en pantanos, visibles en forma de lentes en el área del Saladillo (Cocco et al 2004).

La acción del viento y los remolinos provocados por las diferencias térmicas, asociados a fenómenos de capilaridad, excavaron los cauces abandonados y conformaron hoyadas de deflación. Al acumular partículas de arcilla o arena fina en los bordes sur y norte originaron lunetas de varios cientos de metros de longitud y 2-3 m de altura. Los vientos dominantes eran del sureste, más fuertes y secos que la sudestada actual, que forma neblinas y no tiene capacidad para mover y transportar partículas. En algunas áreas, como en las proximidades de la localidad de Petronila, en el Departamento San Justo, se ha conservado algo del paleosuelo del Holoceno medio, pero en la mayor parte de los perfiles la Formación San Guillermo se encuentra en discordancia sobre la Formación Tezanos Pinto, de color rojizo.

Con el clima actual, las hoyadas de deflación se transformaron en lagunas, y sobre las lunetas se desarrolló un suelo, que en el paleocauce Paranaense, por la abundancia de agua, soporta una vegetación arbórea subtropical a tropical, que se diferencia claramente de la vegetación xerófila del espinal.

La mayor parte de los sitios arqueológicos está en los albardones del Salado y sus afluentes (formados bajo un régimen distinto al actual, con mayor cantidad de agua disponible); en las lunetas de arcilla ubicadas en el borde de las antiguas hoyadas de deflación; y en las lunetas de las lagunas con origen mixto, tectónico y eólico (La Cabral, Palos Negros, La Verde, en el Departamento San Cristóbal; Del Cristal, La Redonda, La Larga, Del Plata, Del Platero, en la cuenca del Saladillo Amargo). En ocasiones las lunetas o "dunas de arcilla" se encuentran disectadas y son cubiertas por el agua, como ocurre en el Complejo Capón-Leyes-Setúbal, donde afloran en forma de islas.

Todos los sitios se caracterizan por la presencia de termoestructuras conocidas popularmente como "botijas" (San Luis, Córdoba) o, en nuestro medio, "hornitos de barro cocido". Generalmente se manifiestan bajo la forma de anillos cortados por la erosión, con paredes de la textura y color del ladrillo a causa de la temperatura, que son rápidamente destruidos por los derrames pluviales. 
Los hornos que mayor información aportan en cuanto a forma y dimensiones, son los que pueden ser localizados en corte longitudinal. Cuando son cortados horizontalmente por la erosión, la altura y el diámetro de la boca se tornan irrelevantes.

Distribución topográfica: pueden aparecer en desplayados, en barrancas de hasta $5 \mathrm{~m}$ de altura y aún en pleno campo, lejos de cualquier curso de agua; totalmente aislados o asociados a sitios definidos.

Morfología: pueden adoptar las siguientes configuraciones: aislados; agrupados, pero sin que las paredes contacten entre si; agrupados en unidades complejas que incluyen dos a nueve «bocas» con paredes comunes (las "bocas" pueden estar alineadas o formando figuras poligonales); en combinaciones que incluyen ejemplares aislados y unidades complejas.

Los que pudimos observar en corte longitudinal eran piriformes, o mejor aún, parecían una vasija enterrada, con base redondeada, boca estrecha y un pequeño cuello. No encontramos los hornitos cupuliformes y de base plana que aparecen en Córdoba y en Mendoza.

Las dimensiones más comunes eran: boca de $15-30 \mathrm{~cm}$; altura total de $40-50 \mathrm{~cm}$; diámetro máximo de 30-45 cm; espesor de las paredes de 3-6 cm; espesor de las paredes engrosadas de $8-9 \mathrm{~cm}$.

En algunos casos se observaron señales de alisado interno de la pared, pero nunca de alisado externo. Algunos tenían fondo bien cocido y otros fondo indefinido, que se confundía con el terreno circundante.

Contenido: generalmente, una capa de $8-10 \mathrm{~cm}$ adherida al fondo, constituida por cenizas, fragmentos de carbón y tierra impregnada de materia carbonosa. En dos ocasiones, restos alimentarios.

Por lo general, los asentamientos fueron breves, y los niveles fértiles no tienen más de 15 a $20 \mathrm{~cm}$ de espesor. Pero existen lugares donde las ocupaciones parecen reiterarse a través del tiempo, como en las lagunas de la cuenca del Saladillo Amargo, donde los sitios tienen hasta $60 \mathrm{~cm}$ de profundidad. Otras veces, como en algunos afluentes del Salado (arroyo San Antonio, arroyo Arizmendi) o en la Laguna La Blanca, en la confluencia del Salado, el arroyo Calchaquí y el arroyo Las Conchas, la cantidad de "hornitos" -más de un centenar, a diversas alturas topográficas- también parece indicar una reocupación periódica de un mismo lugar por poca gente, más que el emplazamiento de una población numerosa.

De cualquier forma siempre resulta difícil determinar qué superficie ocupan estos yacimientos y qué unidades se encuentran asociadas o cercanas unas a otras, porque están bajo la cubierta del suelo actual hasta que la erosión los destapa, y a partir de ese momento su vida es breve ya que son lavados y sus fragmentos acarreados y dispersos por la acción fluvial, los derrames pluviales o la actividad agropecuaria. De tal forma, es muy posible que de los varios cientos de hornos localizados, medidos y mapeados por nosotros en 30 años de actividad arqueológica, hoy queden muy pocos (si es que todavía queda alguno) y que por el contrario exista una cantidad similar que quedó al descubierto en épocas recientes y será destruida en pocos meses o años más. 
Los elementos culturales recuperados en estos sitios son relativamente escasos y en muchos lugares provienen de recolecciones superficiales realizadas en áreas muy extensas, donde forman un palimpsesto. Frecuentemente, aún excavando en la proximidad de "hornitos" localizados en barrancas, el resultado es de pocas decenas de tiestos por metro cúbico de sedimento zarandeado. Los hallazgos, suelen ser de dos tipos:

a) fragmentos de alfarería lisa, incisa y pintada de rojo, generalmente con antiplástico de tiestos molidos. La cerámica incisa presenta diversos tipos de decoración (línea llena, punteado, unguiculado y surco rítmico), formando guardas geométricas paralelas al borde de los recipientes. Abundan también los fragmentos con impresión de cestería y/o de redes, tanto en la parte interna como externa de las vasijas. Probablemente se trate de una técnica de fabricación por embarrado de canastas más que un motivo decorativo, ya que en numerosas ocasiones las huellas fueron parcialmente borradas.

Las formas de los recipientes pueden ser abiertas (fuentes, platos) o cerradas (ollas, contenedores de líquidos), generalmente sin asas, con agujeros para suspensión. Suelen tener las bases redondeadas o aplanadas, pero hacia el oeste de la provincia aparecen bases cóncavas y grandes asas aplanadas, similares a las que frecuentemente se encuentran en Córdoba y en Santiago del Estero. La cerámica con impresiones nos informa indirectamente de la existencia de cestería, redes anudadas, y posiblemente algún tipo de tejidos. Lo mismo parece desprenderse de la presencia de "torteros" (contrapesos del huso de hilar), recortados en fragmentos cerámicos.

b) Elementos líticos tallados y pulidos. Entre los primeros destacan las puntas de proyectil medianas, lanceoladas (con o sin pedúnculo), y triangulares con pedúnculo y aletas elaboradas en xilópalo (madera silicificada), areniscas cuarcíticas o calcedonia. Episódicamente fueron halladas puntas más grandes y pesadas, lanceoladas con bordes dentados, similares a tipos relacionados con Ayampitín. También aparecen raspadores unguiculares, lascas y microlascas, núcleos agotados, instrumentos reciclados (por ejemplo, puntas retomadas en raspador) y afiladores de arenisca. Entre los artefactos pulidos, son muy abundantes las piedras de boleadora y las hachas con cuello completo o $3 / 4$, de medianas a grandes y, a menudo, muy bien pulidas. Generalmente fueron recolectadas durante actividades agrícolas, y suelen estar elaboradas en rocas eruptivas o metamórficas. En un un sitio ubicado a $3 \mathrm{~km}$ del arroyo San Antonio, afluente del Salado, pudimos ubicar un fragmento de filo de hacha elaborado en anfibolita. Prácticamente no se han encontrado instrumentos de hueso (Ceruti 1988, 1992, 1993, 1999, 2000, Ceruti e Iriondo 1980, Rodríguez y Ceruti 1999).

Hasta unos años atrás se conocía muy poco sobre el aspecto físico de estas poblaciones de cazadores-recolectores, porque los enterratorios localizados correspondían a paquetes funerarios, dado que los elementos óseos se erosionan y se destruyen con mucha facilidad al quedar expuestos, o por la inexperiencia y falta de cuidado de quienes intentaron extraerlos. 
Recientemente Gabriel Cocco, en diversos sitios del Sistema Capón-Leyes-Setúbal, localizó y excavó ocho entierros individuales, sin que se advirtiera un patrón definido por sexo o edad: había paquetes funerarios; entierros flexionados; extendidos decúbito dorsal, lateral izquierdo y derecho. Los restos correspondían a adultos maduros (especialmente femeninos), adultos medios y un inmaduro de 3 años, algunos con manifestaciones patológicas (osteoartritis) relacionadas con el proceso de envejecimiento (Cocco et al 2004).

Cronología: la presencia en las aguas del Salado de compuestos de manganeso, hierro y calcio que suelen dar a los restos humanos peso, sonido y solidez y los tiñe con los mismos tonos pardos y negros que la de fauna fósil, avivó durante décadas la utopía del "Hombre Fósil del Cululú". Frenguelli alertó sobre estos falsos fósiles, pero otros, como Vignati, siguieron sosteniendo el origen americano del hombre, y postularon el poblamiento por Bhering de sur a norte: desde la Provincia de Santa Fe, a Siberia. En otro trabajo nos ocupamos del tema y en él se puede encontrar casi toda la bibliografía publicada al respecto (Ceruti 1995).

Contamos con dos fechados de $14 \mathrm{C}$ que nos permiten ubicar a esta entidad cultural alrededor de 2000 años a. p. Uno de ellos, obtenido por INGEIS a partir de partículas de carbón dispersas en el sedimento del sitio Laguna del Plata II (cuenca del Saladillo Amargo), permitió situar el comienzo de la ocupación en $2000 \pm 100$ AP. Para el segundo se utilizó carbón de un hornito excavado en los alrededores de la ciudad de San Cristóbal, en el extremo opuesto de la Provincia. Lo realizó el LATyR y dio una edad absolutamente coincidente: $1980 \pm 60$ AP (ambos sin calibrar).

Este último hallazgo resultó sumamente importante para dilucidar la función que cumplían estas estructuras. La boca del horno estaba cubierta por los restos de una vasija con forma de doble tronco de cono, con base cóncava e impresiones de cestería en las paredes externas. Por debajo, en el relleno, se localizó un hueso largo de ñandú (Rhea sp.) y luego una capa constituida por pequeños huesos y placas dérmicas de un dasipódido. Una parte de los mismos constituía una masa amorfa, muy consolidada por acción térmica, pero otros mostraban todavía la conformación original de la coraza del animal. Por debajo había una capa constituida por fragmentos de carbón, y luego tierra impregnada por cenizas y polvo de carbón. En los alrededores se localizó cerámica y una punta de proyectil lítica lanceolada, fragmentada (Ceruti 1988, 1993).

Se conoce un hallazgo similar realizado por Dante Ruggeroni en el valle del Arroyo El Toba, cerca de Vera, quien en el fondo de un "hornito" encontró seis trozos calcinados de mandíbulas de ciervo, "ubicados prolijamente en forma horizontal y bastante apretujados" (El Litoral 1972).

Los cazadores pedestres perduraron al menos 1.500 años en la Provincia de Santa Fe. Esta opinión está avalada por los siguientes argumentos:

- Un sitio estratificado en la Laguna del Plata, sobre el Saladillo Amargo, con un componente Esperanza y otro Goya-Malabrigo. Este último está compuesto por un entierro secundario con un apéndice zoomorfo, fechado en $1000 \pm 140$ AP. 
- Sitios Esperanza con presencia ocasional de apéndices zoomorfos en la Laguna La Blanca, la costa del Salado en los alrededores del puente María Luisa-Emilia (Departamento Las Colonias) y el Distrito Aguará del Departamento San Cristóbal.

- Un "hornito" en Alejandra, Departamento San Javier, fechado por LATyR en 500 \pm 60 años a.p. (Ceruti 1992, Nóbile et al 1999).

No hay dudas que la estrategia adoptada ante las modificaciones ambientales, cualquiera que haya sido, tuvo resultados ampliamente adaptativos (Borrero 1991).

En otro trabajo (Ceruti 1999) planteamos que esta estrategia fue el desplazamiento estacional, y que Esperanza forma parte de la Tradición Cultural de la Llanura Central, originada en lagunas glaciarias residuales de San Luis y la cuenca del Río Copacabana, en Córdoba, hoy convertidas en salinas. Esta Tradición, pasando por el norte de Córdoba (Mar Chiquita-Los Porongos) habría llegado a la Provincia de Santa Fe, y más tarde, rodeando la Salina de Ambargasta, hasta la alta cuenca del Río Dulce, en Santiago del Estero y Tucumán.

Estas distancias no son tan enormes como parecen. Según lo calculado por Binford, el área central de residencia de una familia esquimal o de una familia bosquimana (área en la que un grupo establece asentamientos o campamentos base a lo largo del ciclo estacional de un año) es de $5.400 \mathrm{~km}^{2}$, "aunque la tierra que explotan, a base de expediciones fuera del campamento principal, puede cubrir un área de 25.000 km" (Binford 1988: 118). Considerando la menor de estas cifras, cada familia se mueve en un radio de unos $42 \mathrm{~km}$ en torno al campamento central. Bastaría que se pongan en contacto cuatro (4) familias para transportar elementos desde la depresión actual del Paraná (por ejemplo, San Javier o Alejandra) hasta el borde de las Salinas Grandes (proximidades de Lucio V. Mansilla, Córdoba), donde hace algunos años tuvimos la oportunidad de localizar "hornitos" en compañía de Gabriel Cocco y el Geólogo Claudio Carignano. Este mecanismo es suficiente para explicar las diferencias en el contexto cerámico. La presencia del material lítico es más complicada, porque no existen canteras en la Provincia de Santa Fe. El xilópalo, las areniscas y el ocre abundan en la Formación Ituzaingó, que aflora en la margen izquierda del Paraná, pero nunca encontramos sitios Esperanza en las islas ni en la costa entrerriana, lo que torna necesaria la intermediación de otro grupo poseedor de medios de navegación, por ejemplo Goya-Malabrigo. Al respecto, no es ocioso recordar que en el componente Goya-Malabrigo del sitio La Palmera 2, Hernandarias, Pcia. de Entre Ríos, localizamos un enterratorio secundario cubierto de piedras y con un colgante de cobre, cuyo origen posible es el área subandina.

Las piedras de boleadora y las hachas pulidas, plantean un grado mayor de interrogante. En el pensamiento de Childe "los términos 'difusión'e 'influencia' carecían de sentido, y en modo alguno constituían explicaciones de los procesos culturales. En vez de ello había que buscar el significado concreto de cada caso concreto, determinando a partir de los registros arqueológicos si cada ejemplo particular de contacto implicaba conquista, federación, visitas amistosas entre jefes vecinos, o formas especiales de intercambio" (Trigger 1980: 45). 
Aunque estamos muy lejos de poder acceder a determinaciones tan precisas, hay que irlas pensando. La materia prima de las hachas, y las hachas mismas, tienen que venir de las Sierras Centrales o de las Sierras Subandinas. Descartando Córdoba, donde al parecer son tardías, el proveedor de las mismas puede ser la Cultura Candelaria, en Tucumán-Salta o San Francisco, o en Jujuy como ya lo sugirieron Von Hauenschild (1949) y Gómez (1966).

Conviene recordar que Roque Gómez localizó hornitos en Tobar, sobre el río Salí (Gómez 1974), y que Dougherty los encontró en estratigrafía en El Piquete (arroyo El Quemado, $5 \mathrm{~km}$ al este del río San Francisco), en El Cadillal (aeropuerto de Jujuy) y en el Saladillo Redondo (Dougherty 1975 y comunicación personal).

Estamos habituados a valorar las acciones humanas en términos de entropía, y nos cuesta comprender que se derroche tanta energía en obtener y proteger un bien preciado (por ejemplo, un hacha), que en un ambiente puede ser una herramienta de trabajo, en otro una insignia de mando y en otro, la representación de la divinidad. Es probable que las hachas del norte y centro de Santa Fe sean elementos utilitarios, y estén relacionadas con determinado tipo de vegetación. Pero también pueden estar indicando el tránsito entre diversos ecosistemas, como también ocurre en la zona de Venado Tuerto (Departamento General López), al sur de la provincia de Santa Fe, donde se encuentran hachas pero donde no existió árbol alguno entre el Lujanense y el siglo XIX.

Volviendo a los orígenes de la Tradición de la Llanura Central, es muy llamativo que el área de distribución de los sitios más antiguos (San Luis, cuenca del Copacabana, Laguna Mar Chiquita, río Salado y paleocauce Paranaense) coincida con lo que Bruniard (2001-2002) considera una discontinuidad climática que divide los núcleos del Chaco Occidental y Chaco Oriental y el de la Pampa, y cuyos reflejos fitogeográficos actuales son el Chaco Serrano y el Monte Periestépico.

Como dice este autor: "en lo que respecta al límite meridional o franja de contacto entre el Chaco y la Pampa, hay coincidencia en atribuir el contraste fitogeográfico que representan estos paisajes a los factores climáticos. Los límites biológicos establecidos entre estos ámbitos en algunos casos son lineales (Lorentz 1876, Hauman 1920, Kühn 1930, Parodi 1934 y 1935) y todos ellos se inscriben dentro de la faja de discontinuidad climática; en otros casos se han señalado franjas ecotonales o nuevas formaciones transicionales como son las propuestas de Roveretto (1914), el 'Monte Periestépico' de Frenguelli (1941) o la 'Provincia del Espinal' de Cabrera (1953), cuyos desarrollos coinciden notablemente con el tramo zonal de la franja crítica que localizamos entre $\operatorname{los} 30^{\circ}$ y $32^{\circ} \mathrm{S}$. Esta franja es indicativa también del límite meridional de las palmeras, de los quebrachos -elementos típicamente chaqueños- y de los cultivos subtropicales como la caña de azúcar, el tabaco y el algodón”. (Bruniard 2004: 32).

Los "hornos" más antiguos de San Luis, que fueron fotografiados por Guiñazú (ver Ceruti 1999) estaban por debajo del "Suelo Los Toldos", anterior al comienzo del Período Seco del 3500 a.p. y lo mismo ocurre con los que vimos en el Río Copacabana, en Córdoba. En Petronila (Departamento San Justo, Santa Fe), los "hornos" que localizamos con Iriondo y C. Manavella también se abrían por debajo del Horizonte B decapitado de un paleosuelo correspondiente al Hypsitermal. 
De lo expuesto se podría inferir que los primeros asentamientos se produjeron bajo un clima sensiblemente similar al actual, y que los desplazamientos posteriores hacia la cuenca del Salí-Dulce y el Chaco son una respuesta al recrudecimiento de las condiciones de aridez y al avance del ambiente pampásico hacia el norte. La persistencia de esta Tradición en algunas zonas de San Luis, Mendoza, Córdoba y Santa Fe hasta el 1000 a.p. y posiblemente hasta épocas históricas, sería consecuencia de mecanismos adaptativos y de la disponibilidad de agua en ambientes muy específicos.

En Santa Fe, en particular, algunas lagunas del paleocauce se secan completamente en verano, pero otras tienen fondo de arena y son permanentes, indicando que la erosión eólica se detuvo al llegar a los sedimentos gruesos del relleno, pertenecientes a la Formación Ituzaingó, por los que circula la freática (Iriondo 1987).

En cuanto a la Laguna Blanca y las restantes lagunas permanentes del extremo oeste de la provincia, están sobre la faja de paleocauces enterrados del Salado, de edad pleistocénica, un acuífero que se recarga con las lluvias de las sierras de Córdoba. (Filí y Tujchneider 1977, Iriondo 1987, 2000, Montaño et al 1998).

Dice Iriondo: "Los paleocaues están cubiertos por una carpeta de loess de 6 a 8 metros de espesor, aunque son todavía visibles en el campo y en fotografías aéreas. Son tortuosos, con un ancho de hasta 200 metros y transportaban arena bien seleccionada. Los paleocauces de diferentes edades y direcciones se superponen y cruzan en un patrón irregular. La arena que contienen es una reserva de agua subterránea de baja salinidad, lo que resulta un hecho significativo en esa zona con escasos recursos hídricos" (Iriondo 2000: 42).

En opinión de Filí y Tujchneider "el área de recarga principal se localiza en los pedimentos de las Sierras Pampeanas, con gradientes que van disminuyendo hacia el este, con nivel de descarga regional en el valle del río Paraná. El escurrimiento desde la zona serrana hacia la Laguna de Mar Chiquita, parece entrar a territorio santafesino transponiendo subterráneamente la falla Tostado-Selva-San Francisco. A este hecho podría atribuirse la concordancia entre inundaciones en el área de Mar Chiquita y el crecimiento de los cuerpos de agua superficial en la bajada del 'domo occidental', tal como se observa en imágenes satelitarias” (Filí y Tujchneider 1977: 111).

El mismo fenómeno se produce en Villa Cañás, Departamento General López, en el otro extremo de la provincia, donde las lagunas son alimentadas subterráneamente por los derrames del río Quinto (Ceruti 1992 y 1993, Iriondo 1987 y 1994). Coincidentemente con el avance de los procesos de aridificación, hace 2.000 años un pueblo de raigambre pampeana ocupó las lunetas que bordean las antiguas hoyadas de deflación de un paleocauce enterrado del río Tercero (14C: $1880 \pm 90$ y $2140 \pm 80$ a.p. calibrado, Basabilbaso com. pers.).

\section{El período histórico}

El 15 de enero de 1544, en algún lugar de la Provincia de Salavina murió Diego de Rojas, herido por una flecha envenenada. Este fue el primer encuentro de los españoles con los juríes, indios flecheros de la llanura. "Eran estos indios gente alta, bien dispuesta, y 
traen conforme a su estatura los arcos con que pelean. Las flechas que tiran llevan ponzoña que mata rabiando en ocho o diez días y, desde que comienza a obrar, los heridos se dan de golpes y cabezadas y la herida no era más que un rasguño; empero, a tercero día obró la hierba..." (Diego Fernández en Berberián 1967: 41).

Aunque las crónicas no lo dicen expresamente, hay acuerdo en que estas flechas debieron ser de hueso, tal vez con algún agregado, ya que se habla de "púas" que eran las encargadas de llevar el veneno: "algunos murieron por no poder hallar las púas de las flechas que son a manera de agujas" (Diego Fernández en Berberián 1967: 50); "las púas de la flecha, que de industria las aguzan con rara sutileza, y ponen en tal disposición, que al arrancar la flecha de la herida queden dentro las púas..." (Lozano en Piossek Prebisch, 1986: 43).

Estas puntas son relativamente abundantes en Santiago del Estero. Lorandi las encontró en Quimili Paso y El Veinte asociadas con puntas tubulares huecas de hueso de pájaro y materiales Sunchituyoj: "largas, dos de ellas con acanaladura en una de sus caras" (Lorandi y Carrió 1975). En otro trabajo, las atribuye a la Fase "Las Lomas del Veinte", la más antigua de la Tradición Chaco-Santiagueña, del 1000-1200 d.C (Lorandi et al. 1975).

También son comunes en Córdoba. Fueron mencionadas por Outes en la Estación I del Observatorio, Cruz del Eje y el Lago San Roque. Por Nimo, en Laguna Honda, con "hornitos". Por González en Pampa de Olaen y Villa Rumipal. Marcelino et al (1967), que las fechan en el Dique los Molinos en $903 \pm 150$ AP, dicen que son muy delgadas, pulidas y lisas, mientras que las de Santiago del Estero suelen estar grabadas.

González y Pérez (1972) las vinculan a pueblos relacionados con el Chaco Santiagueño: en Córdoba con los sanavirones, y en el Valle de Hualfín (Catamarca) con los que incendiaron el Pucará de Asampay (cultura Belen) y asesinaron y decapitaron a sus habitantes.

Aparicio (1942) publicó materiales hallados por el geólogo Francisco Kühn en Laguna de Los Porongos, entre ellos una punta de flecha "chata, triangular, isósceles, con aletas y pequeño pedúnculo", cuentas en valvas de Strophocheilus lorentzianus, la sepultura de un niño y un adulto sin los cráneos (el niño, con cinco placas de gliptodonte) y cerámica mezclada. Algunos fragmentos propios de las Sierras de Córdoba, otros con surco rítmico "que mezclados con material paranaense no podrían luego reconocerse", y otros con impresiones de redes y cestería.

En la Provincia de Santa Fe, Serrano (1932) reportó un hallazgo realizado por dos empleados del Museo de Ciencias Naturales y Antropológicas de Paraná -Jovito Ríos y Juan Cano- en la costa de la Laguna Los Molles, Departamento San Cristóbal. Se trataba de "huesos humanos correspondientes a varios esqueletos, tres objetos de hueso, fragmentos de alfarerías y cáscaras de huevos de ñandú, que al parecer acompañaban a uno de los esqueletos". Los fragmentos de alfarería (que no pudimos encontrar en el Museo "Antonio Serrano" de Paraná) tienen similitud con algunos procedentes de Laguna de los Porongos, que vimos en el Museo de San Guillermo, o con otros procedentes de sitios Esperanza del Departamento San Cristóbal: fragmentos de recipientes troncocónicos con base plana y 
cóncava, con impresiones de cestería o redes; bordes incisos (punteados y de surco rítmico) con agujeros de suspensión; frag. de recipientes globulares con perfil inflexionado y bordes lisos o incisos; antiplástico de tiestos molidos; asas en arco, grandes; pintura roja de hematita.

Las puntas están confeccionadas en hueso de ñandú (Rhea americana) y se conservan en el Museo "Antonio Serrano": dos son alargadas, chatas, acanaladas, con aletas y pequeño pedúnculo; la tercera, descrita por Serrano como "espátula" es una punta hueca, similar a una de la Estación I del Observatorio, ilustrada por Outes, o a las descriptas por Lorandi para Las Lomas del Veinte.

Tentativamente, teniendo en cuenta los fechados de Córdoba y Santiago del Estero, las ubicamos en el Período Histórico o inmediatamente antes, aunque podrían ser más antiguas y formar parte de una facie particular de la Laguna de los Porongos.

A fines del siglo XVII y comienzos del XVIII, los grupos chaqueños se expandieron hacia el sur en forma imparable. Primero los calchaqui (que dieron su nombre al Valle del Golondrinas, conocido desde entonces como "Valle Calchaquí") y luego los de habla Guaycurú, especialmente abipones, mocovíes y tobas. Estos desplazamientos tienen que ver, por una parte, con la adopción del caballo, y por otra parte, con las profundas alteraciones iniciadas en el siglo anterior en lo profundo del Chaco, por presión de los avá ("chiriguano") sobre los wichí o mataco, y de éstos sobre los guaycurú y los lule, que avanzaban sobre la llanura de Santiago del Estero en momentos en que se producía la "Entrada" de Diego de Rojas. Los soldados de este último oyeron hablar "de otra provincia hacia un río que llevaba el agua colorada, y decían que los indios de aquella provincia les hacían guerra, y que los que llevaban cautivos los comían y llegó Diego Alvarez con sus compañeros y dio nueva que habían hallado una provincia de indios que comían carne humana y traían coronas en las cabezas como frailes; y con esto cesó la salida por entonces..."(Diego Fernández en Berberián 1987: 61).

Aparentemente, el primer pueblo ecuestre fue el abipón o callagá, originario del Bermejo, que hacia 1700 invadió Santa Fe, Corrientes, parte de Santiago del Estero y Córdoba. Los mocoví, también del Bermejo, habían participado (1632) en la destrucción de Concepción del Bermejo, y unidos a los abipón y los toba atacaron Salta, Tucumán, Esteco, Santiago del Estero y Córdoba. A partir de 1710, luego de la expedición de D. Esteban de Urízar y Araspacochaga, se replegaron del Tucumán, y avanzaron especialmente sobre Santa Fe y sus estancias. Los toba o tocovit ocuparon hasta el siglo XVIII la sabana del Chaco Medio, entre el Bermejo, el Pilcomayo y el valle de San Francisco (Jujuy). Posteriormente fueron desplazados del sector occidental por los wichí. Unidas, las tres etnias Guaycurú, se desplazaron por todo el sur del Chaco, desde las Salinas Grandes de Santiago del Estero hasta el Paraná, y por el sur hasta el nordeste de Córdoba, incluyendo la Cuenca de Los Porongos-Mar Chiquita (Alemán, 1994 1997, Cervera 1970, Maeder y Gutiérrez 1995).

Los mocoví fueron reducidos en San Javier en 1743, y los abipón en San Jerónimo del Rey (Reconquista) en 1749. A partir de entonces, algunos de ellos se constituyeron en fuerza de choque de los españoles contra los grupos montaraces del Chaco. Las dos 
reducciones cortaron el corredor que se extendía entre el Sistema de los Saladillos y el Paraná, pero dejaron libre el corredor del Golondrinas-Calchaquí.

En la Provincia de Santa Fe, no se investigó arqueológicamente ningún sitio histórico correspondiente a grupos indígenas no reducidos de los siglos XVI-XIX. En los materiales extraídos de Santa Fe la Vieja (volcada a la cuenca del Paraná) hay unas pocas decenas de fragmentos de cerámica Averías, que no fueron estudiados todavía y plantean las relaciones de los encomenderos santafesinos con Santiago del Estero.

En 1977 excavamos un recinto y un basurero correspondientes a la Reducción de San Javier de Indios Mocovíes, donde fuera doctrinero el Padre Florián Paucke entre 1750 y 1768 (Ceruti 1983, Paucke 1942). La mayoría de los materiales recuperados son de origen europeo, pero también se encontró cerámica indígena correspondiente a dos tipos: San Javier Ordinario, con arena mediana y hueso molido ( $11 \%$ de la muestra) y San Javier Ordinario con tiestos. La presencia de hueso molido, concordante con lo expuesto por Paucke, constituye una novedad para la Arqueología santafesina. Las formas, reconstruidas a partir de fragmentos muy pequeños, concordaban en parte con las vasijas con cintura y las "caramañolas" ilustradas por Paucke, comunes entre los chaqueños modernos. También se recuperó una soberbia punta de lanza de hierro, subtriangular con base recta y bordes redondeados, de $18 \mathrm{~cm}$ de largo.

Dos años antes de la expulsión de los jesuitas se inauguró la Reducción de San Pedro. Tras duras discusiones con el teniente de Gobernador Francisco A. de Vera Muxica, que pretendía fundar en la laguna La Blanca (un lugar que se negaba, y cuya agua no podían beber ni las vacas porque se empantanaban, según Paucke), se eligió otro sitio ubicado al oeste de la laguna Larga y el curso del Saladillo Amargo. "Una colina que estaba en pleno bosque: junto a muchos lagos grandes de agua no del todo dulce sino algo salobre que era aún buena a beber por el ganado. Al otro lado de esta colina hallamos un río angosto que allá tenía hondos remansos muy ricos en peces...”. Este arroyo, llamado Inspín Chico y actualmente San Pedro, tiene agua dulce de vertientes y desemboca en la Laguna del Plata, en campos de lo que fuera la Estancia San Pedro Grande del Coronel Plácido Obligado. El lugar es una isleta de monte muy tupida conocida como "El Cantón", donde en alguna oportunidad se localizó un pozo para agua, y restos de un corral y un brete con refuerzos de hierro.

Durante el siglo XVIII, durante la "Pequeña Edad de Hielo", las sequías y las invasiones indígenas condicionaron las rutas. En un plano datado en 1790, y reproducido por Cervera y por Alemán (Cervera 1970, Alemán 1994-1997), se trazó la línea de fortines y las rutas al interior: el Salado se interrumpía al llegar a Tostado, y el Río Segundo se sumía en un estero aguas abajo de El Tío, sin alcanzar la Mar Chiquita, que estaba seca y transitable como si fuera un bañado temporario. Solamente Los Porongos aparecen indicados como lagunas permanentes, y aún allí a veces se tenían que cavar pozos para dar de beber a las tropillas de mulas que se llevaban al Alto Perú.

A fines del siglo XIX se intentó crear un nuevo camino, remontando el Salado en barco desde Santa Fe hasta Santiago del Estero. En febrero de 1857 Esteban Ramos y 
Rubert llegó a Monte Aguará, donde desemboca el arroyo Las Conchas en el Salado, y de allí no pudo seguir por falta de agua y por los troncos que taponaban el cauce. Los hombres del Cacique mocoví Bonifacio le comunicaron que la creciente no viene hasta "últimos de Cuaresma, y con mayor razón este año por la gran seca" (Rams y Rubert 1969: 46). Estuvo allí hasta el 21 de marzo en que renunció, desalentado, a seguir la exploración.

Monte Aguará abarcaba todo el actual Distrito Aguará Grande (Departamento San Cristóbal) y parte del Departamento Las Colonias y era por entonces el reducto indígena más importante del centro-oeste santafesino. Durante el tiempo que duró su estadía, Rams y Rubert recibió la visita de los siguientes caciques, todos mocovíes: Cacique Principal José, con 5 oficiales y 80 soldados; Cacique Bonifacio, con 4 oficiales y 60 soldados; Cacique Roque, "indio montarás", con 5 soldados (era hombre de Bonifacio); Cacique Felipe (hermano de José y tío de Bonifacio), con 28 soldados; Cacique Nolasco.

Se consigna que todos los indios venían montados a caballo y armados con lanzas. Con ellos traían mujeres y chicos (incluyendo la esposa y los dos hijos de Bonifacio), algunos de brazos. Se menciona una cautiva con dos hijas de brazos, y dos o tres cautivos que hacían de intérpretes y mensajeros de los indios. Como intérprete de Rams y Rubert actuaba el Comandante D. Antonio Crespo.

Por aquella época el Cacique Principal José había estado en la ciudad de Santa Fe, donde firmó con el Gobierno Provincial un pacto sobre mutua devolución de cautivos y recibió el grado de Teniente Coronel. Mantenía comunicaciones con el Gobierno provincial, que le había anticipado la llegada del vapor y "recomendado especialmente a los miembros de la expedición".

La tropa indígena acampó en una laguna al costado del Salado, de donde sacaban agua, porque la del río estaba muy salobre. Se comunicaban los movimientos entre sí mediante incendios de campos. El cacique Bonifacio envió emisarios en canoa a Santa Fe y Paraná llevando cartas y recibió respuesta en el término de dos días.

Para terminar de decidir a Rams y Rubert, desde Santiago del Estero llegó por tierra el General Taboada, que entró por la laguna Palos Negros, comunicando que el río estaba bajo en toda la línea y no permitiría el paso.

El problema del agua seguía siendo decisivo hacia 1870, cuando se inició la última acción del Ejército Nacional contra las tribus independientes del Chaco. Tuvimos oportunidad de excavar en el Fortín Aguará, al oeste del sitio donde se detuvo Rams y Rubert, a $2 \mathrm{~km}$ al sur del Salado y cerca de un zanjón que desemboca en la laguna Los Molles. Estaba alimentado por dos pozos de balde, ubicado en el Sector Centro de la línea de defensa del Coronel Manuel Obligado, y nunca entró en combate en sus efímeros dos años de vida, aunque tuvo importancia como punto de reunión en el traslado de la línea de fronteras (Ceruti y Cocco 1998).

Este Sector sufría las presiones más intensas, porque las invasiones indígenas entraban a Santa Fe, Córdoba y Santiago del Estero siguiendo el curso del arroyo Golondrinas, utilizando sendas cubiertas por el follaje abiertas en los montes de El Impenetrable. El punto de concentración de los malones estaba en Nasuisaty, sobre el 
Golondrinas (posiblemente la laguna que ahora recibe el nombre de El Isoatí). Allí se reunían los tobas, mocovíes, montaraces y espineros, y de allí partía un "ancho camino" que se dirigía al norte, pasaba por la laguna Palo Pelado y llegaba al Bermejo.

Según Wyfsocki (1872), en esta línea se encontraban las últimas aguadas que podían ser utilizadas por las caballadas indígenas en los avances, y por las tropas de hacienda que solían traer al regreso de las incursiones. Sin esas aguadas, ni los indígenas podían avanzar hacia el sur en forma masiva, ni podían regresar al Bermejo con ganado, y además se les cortaba la provisión de víveres, que procedía fundamentalmente de San Javier y las islas del Paraná. El principio del fin fue la toma de Nasuisaty, donde Obligado instaló la Comandancia.

\section{Conclusiones}

Los movimientos prehispánicos de pueblos en el norte de la actual Provincia de Santa Fe están relacionados en gran medida con el comportamiento de las formaciones vegetales, entendidas como respuestas bióticas dinámicas al clima, la topografía y la disponibilidad de agua en el subsuelo, y con el conjunto de recursos que ellas involucran.

La formación denominada Espinal ocupa una discontinuidad entre el ambiente chaqueño y el pampeano, constituyendo un ecotono entre las formaciones vegetales típicas de ambos, pero su ubicación debió variar en cada fase climática del Holoceno. La llanura aluvial del Paraná medio, en tanto, aunque sujeta también a cambios importantes relacionados con las variaciones de clima y caudal, debió ser más predecible en materia de recursos, permitiendo una mayor estabilidad de las poblaciones ribereñas.

El avance del ambiente pampásico hacia el norte durante las fases áridas facilitó la entrada de los primeros pobladores conocidos, pueblos cazadores-recolectores pedestres que llegaron desde el sudoeste, en tanto que durante el pico climático húmedo del 1000 d.C. se produjo la máxima expansión de los cazadores-pescadores-recolectores con canoa, que en ese momento ocuparon todo el Paraná medio, alcanzaron el delta y por éste llegaron al Uruguay inferior y medio.

La adopción del caballo en los siglos XVII-XVIII y el atractivo que representaban las estancias, reducciones y primeras poblaciones españolas, motivó la llegada de los grupos chaqueños (primero los calchaquíes, después los abipones, mocovíes y tobas), que acorralaron y en parte obligaron a mudar a Santa Fe la Vieja y tuvieron a mal traer a Santa $\mathrm{Fe}$ de la Veracruz. El caballo, de cualquier forma, si bien redujo enormemente las distancias hasta el punto que las tribus ecuestres transitaban en pocos días desde el Pilcomayo o el Bermejo hasta el centro de Santa Fe, no significó la independencia del ambiente. El control del agua siguió siendo fundamental, tanto para ingresar con las caballadas frescas como para regresar hacia el Chaco con los arreos de ganado vacuno, por lo que el malón fue siempre una operación de guerra planificada, que implicaba diplomacia previa, operaciones de inteligencia, aprovisionamiento y protección de la retirada. 


\section{Bibliografía}

Aleman, Bernardo E. 1994-1997. Santa Fe y sus aborígenes. Junta Provincial de Estudios Históricos, Partes I y II, Santa Fe.

Aparicio, Francisco 1942. "Arqueologia de la Laguna de los Porongos”. En: Relaciones de la Sociedad Argentina de Antropología, III, p. 45-51, Buenos Aires.

Berberian, Eduardo E. 1987. Crónicas del Tucumán, siglo XVI, Comechingonia, Córdoba.

Borrero, Luis Alberto 1991. "Los 'modelos de situaciones excepcionales' y el estudio de las sociedades de cazadores y recolectores". En: Comechingonia, 8(7):109-127, Córdoba.

Bruniard, Enrique . 2004. "El ámbito subtropical en la República Argentina (Climatología dinámica y límites climáticos”. En: Folia Histórica del Nordeste 15:15-36, Instituto de Investigaciones Geohistóricas -CONICET, Resistencia.

Calandra, H. A.; S. Ferrarini; M.G. Mendez; S.A. Salceda; M.T. Iglesias y V. Lema. 2003. "Potencialidad sustentadora de la Región Meridional del Gran Chaco". En: Actas del Primer Congreso Nacional de Arqueología Histórica, pág. 435-445, Corregidor, Buenos Aires.

Campos, Guillermo. 2003. "Análisis litológico de la matriz sedimentaria de los sitios arqueológicos La Lechuza y Puesto Perita". En: Revista de la Escuela de Antropología, VIII: 211-222, Rosario.

Castellanos, Alfredo. 1968. Desplazamientos naturales, en abanico, del río Salado del Norte en la llanura Chaco-santiagueño-santafesina. Publicaciones del Instituto de Fisiografía y Geología, LII, Rosario.

Ceruti, Carlos N. 1983. “La Reducción de San Francisco Javier, Dpto. San Javier, Provincia de Santa Fe". Morresi, Eldo S. y Ramón Gutiérrez (Directores), Presencia hispánica en la Arqueología Argentina, 2:455-486. Museo Regional de Antropología «Juan E. Martinet» e Instituto de Historia, UNNE, Resistencia.

Ceruti, Carlos N. 1988. "Modificación ambiental y adaptación cultural en la cuenca del Paraná Medio". Trabajo presentado en el Simposio "Estrategias Adaptativas en Arqueología”, del IX Congreso Nacional de Arqueología Argentina, Buenos Aires.

Ceruti, Carlos N. 1992. "Cambios climáticos y poblaciones prehistóricas en el Litoral Argentino". En: M. Iriondo (Ed.), El Holoceno en la Argentina, I:39-49, CADINQUA, Paraná.

Ceruti, Carlos N. 1993. "Arqueología”. En: Nueva Enciclopedia de la Provincia de Santa Fe, IV:7-80, Ed. Sudamérica Santa Fe, Santa Fe.

Ceruti, Carlos N. 1995. "Reinterpretación de algunos sitios arqueológicos tempranos en la Pcia. de Santa Fe: cuenca del Salado-Cululú”. En: Actas del XI Congreso Nacional de Arqueología Argentina - Rev. del Museo de Historia Nat. de San Rafael, XXVII(1/4):103-121. San Rafael.

Ceruti, Carlos N. 1999. "La Tradición de las Llanuras Centrales". En: Homenaje a Alberto Rex González, 50 años de aportes al desarrollo y la consolidación de la Antropología Argentina (Buenos Aires, 1994), p. 181-197. FADA-Facultad de Filosofía y Letras de la UBA, Buenos Aires.

Ceruti, Carlos N. 2000. "Ríos y praderas. Los pueblos del Litoral”. En: Nueva Historia Argentina, Tomo I, Cap. III: 105-146. Ed. Sudamericana, Buenos Aires.

Ceruti, Carlos N. 2003. "Entidades culturales presentes en la cuenca del Paraná Medio (margen entrerriana)". En: Mundo de Antes (3):111-135, Tucumán.

Ceruti, Carlos N. y Gabriel Cocco. 1998. "Un proyecto de Arqueología Histórica: Fortín Aguará, Estancia “El Lucero", Aguará Grande, Dpto. San Cristóbal (Provincia de Santa Fe)". En: América (14):111;121, Santa Fe.

Ceruti, Carlos N. y Martín H. Iriondo. 1980. “Aporte al conocimiento del Holoceno de la Pcia. de Santa Fe (cuenca del Saladillo Amargo) y su relación con los asentamientos humanos 
prehispánicos". Trabajo presentado en: Primera Reunión de Comunicaciones de la Asociación de Ciencias Naturales del Litoral, Santa Fe (ms).

Cervera, Federico G. 1970. Reseña histórica del Período Colonial. En: Comisión Redactora de la Historia de las Instituciones de la Provincia de Santa Fe, III: 2-110, Santa Fe.

Cocco, Gabriel; María C. Barboza y María P. Ayuso. 2004. "La interpretación del registro bioarqueológico en el sector sur del Bajo de los Saladillos, Provincia de Santa Fe". En: Revista de la Escuela de Antropología, IX: 173-186, Rosario.

Cornero, Silvia. 1999. "Enterratorios humanos en el Litoral: sitio La Lechuza, Alejandra, Pcia. de Santa Fe". En: Actas del XII Congreso Nacional de Arqueología Argentina, III: 384-388, Cristina Diez Marín (Ed.), Facultad de Ciencias Naturales y Museo de La Plata.

Cornero, S. y R. Puche. 1995. "Análisis de elementos traza en un grupo de pescadores prehistóricos del Paraná Medio (Arroyo Aguilar, Santa Fe)”. En: Revista de la Escuela de Antropología, III: 11-16, Rosario.

Echegoy, Carlos. 1993. Arqueología del Departamento General Obligado: arqueología de campo. Museo Municipal de Arqueología y paleontología de Reconquista, mimeografiado.

Echegoy, Carlos. 1994. Arqueología del Paraná: los fechados C14 de Arroyo Aguiar. Museo Municipal de Arqueología y Paleontología de Reconquista, mimeografiado.

El Litoral. 19/2/1972. Hallazgo arqueológico en el arroyo El Toba, Santa Fe.

Fili, Mario Felipe y Ofelia Clara Tujchneider. 1977. "Características regionales del subsuelo de la Provincia de Santa Fe (Argentina)”. En: Rev. Asoc. Cienc. Nat. del Litoral, (8):105-113, Santo Tomé.

Furlong, Guillermo S.J. 1955. Joaquin Camaño S.J. y su «Noticias del Gran Chaco» (1778). Librería del Plata, Buenos Aires.

Gómez, Roque M. 1966. La Cultura de Las Mercedes (Contribución a su estudio), 28 p., Santiago del Estero.

Gonzalez, Alberto R. y J. A. Pérez. 1972. Argentina indígena, vísperas de la conquista. Ed. Paidós, Bs. As.

Hauenschild Jorge. 1949. "Ensayo de clasificación de la documentación arqueológica de Santiago del Estero". En: Revista de la Universidad Nacional de Córdoba, XXXVI, (1) 82 p., Córdoba.

Iriondo, Martín H. 1983. "Geomorfología de la cuenca inferior del Río Salado como base para la investigación hidrológica". En: Actas del Coloquio de Olavarría "Hidrología de las grandes llanuras”, UNESCO, Comité Nacional para el Programa Hidrológico Internacional, III: 12071238, Buenos Aires.

Iriondo, Martín H. 1985. Geología y Geomorfología: su importancia y relación con la Edafología. Publicación Miscelánea No 30, INTA (Estación Experimental Regional Agropecuaria Rafaela), Rafaela.

Iriondo, Martín H. 1987. Geomorfología y Cuaternario de la Provincia de Santa Fe (Argentina). D’Orbignyana , 4: 1-54, Corrientes.

Iriondo, Martín H. 1992. "El Chaco”. En: M. Iriondo (Ed.), El Holoceno en la Argentina, 1:50-63, CADINQUA, Paraná.

Iriondo, Martín H. 2000. "Características de las cuencas de aporte: aspectos geológicos y gemorfológicos”. En: El río Paraná en su tramo medio, Carlos Paoli y Mario Schreider (Ed), I: 35-53, Universidad Nacional del Litoral, Santa Fe.

Kurc, Alicia N. 1995. "La disponibilidad de los recursos y su relación con el uso del espacio en el Paraná Medio". En: Actas y Memorias del XI Congreso Nacional de Arqueología Argentina, Rev. del Museo de Historia Natural de San Rafael, XXVII(1/4):75-81, San Rafael. 
Kurc, Alicia N. y María T. Carrara 2001. "Prospecciones arqueológicas en el corredor paranaensePcia. de Santa Fe, Argentina”. En: Actas del IX Congreso Nacional de Arqueología: arqueología uruguaya hacia el fin del milenio, II: 533-538, Montevideo.

Lafon, Ciro R. 1971. "Introducción a la arqueología del Nordeste Argentino". En: Relaciones de la Sociedad Argentina de Antropología, N.S., V(2):119-152, Buenos Aires.

Lorandi, Ana María y Nélida Carrio. 1975. "Informe sobre las investigaciones arqueológicas en Santiago del Estero". En: Actas y Trabajos del Primer Congreso de Arqueología Argentina, Buenos Aires.

Lorandi, Ana María; Raúl Arias; María Elena Gonaldi; Eleonora N. Mulvany y Loredana H. M. Nordio. 1975. "La Fase Las Lomas de la Tradición Cultural Chaco-Santiagueña". En: Etnia, 21: Art. 84, 12 p., Olavarría.

Maeder, Ernesto J. y Ramón Gutierrez. 1995. Atlas histórico del Nordeste Argentino, Instituto de Investigaciones Geohistóricas (CONICET, UNNE, Resistencia.

Marcellino, Eduardo J., Eduardo E. Berberian y José A. Perez . 1967. El Yacimiento Arqueológico de Los Molinos (Dpto. Calamuchita, Córdoba), Universidad Nacional de Córdoba, Instituto de Antropología, XXVI, Córdoba.

Montaño, Jorge; Ofelia Tujchneider; Miguel Auge; Mario FILI; Marta Paris; Mónica D’elia; Marcela Perez; María Inés Nagy; Paula Collazo y Pablo Decoud. 1998. Sistema Acuífero Guaraní: capítulo argentino-uruguayo, Universidad Nacional del Litoral, Santa Fe.

Nóbile, Juan C.; Carlos N. Ceruti y Silvia Cornero. 1999. "Investigaciones arqueológicas en el área de Alejandra, Dpto. San Javier, Pcia. de Santa Fe". En: Actas del XII Congreso Nacional de Arqueología Argentina, III:389-393, Cristina Díez Marín (Ed.), La Plata.

Paucke, Florian, S.J. 1942. Hacia allá y para acá (Una estada entre los indios mocobíes, 1749-1767). Universidad Nacional de Tucumán, Publicación No 324, Tucumán- Buenos Aires

Piossek Prebisch, Teresa. 1986. Los Hombres de la Entrada, Editor, San Miguel de Tucumán.

Rams y Rubert, Esteban. 1969 [1857]. Diario de Viaje. En: Boletín del Archivo General de la Provincia, I(1):45-61, Sta. Fe.

Rodríguez, Jorge A. 1992. “Arqueología del sudeste de Sudamérica”. En: Prehistoria Sudamericana: nuevas perspectivas, p. 177-209. Betty Meggers (Ed.), Taraxacum, Washington.

Rodríguez, Jorge A. y Carlos N. Ceruti. 1999. "Las tierra bajas del Nordeste y litoral mesopotámico". En: Nueva Historia de la Nación Argentina, T.I-Primera Parte, Cap. 4:109-133. Academia Nacional de la Historia. Planeta, Buenos Aires.

Roverano, Andrés A. 1983. Santa Fe la Vieja. Colmegna, Santa Fe.

Salceda, Susana A. y Horacio A. Calandra. 2003. "La planicie chaqueña: orígenes de su historia". En: Duodecimo Congreso Nacional y Regional de Historia Argentina, Academia Nacional de la Historia, Buenos Aires.

Schmitz, Pedro Ignacio; Carlos N. Ceruti; Alberto R. González y Antonia Rizzo. 1972. "Investigaciones arqueológicas en la zona de Goya (Corrientes, Rep. Argentina)”. En: Dédalo, VIII (15): 11-121, Sao Paulo.

Serrano, Antonio. 1932. Material arqueológico del Departamento San Cristóbal (Provincia de Santa Fe). En: Quid Novi, 3: 1-4. Rosario.

Serrano, Antonio. 1938. La etnografía antigua de Santiago del Estero y la llamada Civilización Chaco-Santiagueña. Predassi, Paraná.

Trigger, Bruce G. 1980. La Revolución Arqueológica. El pensamiento de Gordon Childe. Fontamara, Barcelona.

Wyfsocki, Jordán. 1872. "Informe del Capitán de Ingenieros Don...al Sr. Ministro de Guerra y 
Marina, elevado el 20 de diciembre de 1872”. En: Roselli, Manuel H. 1980. Historia de Reconquista, Primera Parte:119-127, Ed. Of., Reconquista.

\title{
Resumen
}

El presente trabajo intenta relacionar los desplazamientos de población humana registrados en el dominio chaqueño de la provincia de Santa Fe con los cambios de clima del Holoceno y el aprovechamiento del agua. Esta situación motivó la ocupación de albardones así como el borde de hoyadas de deflación ubicadas en paleocauces; y el desplazamiento estacional como estrategia adaptativa por parte de los cazadores-recolectores de la entidad cultural Esperanza. Además la importancia del agua continuó en épocas posthispánicas, aún después de la adopción del caballo por los grupos chaqueños, siendo este un factor determinante en la ubicación de la Reducción Jesuítica de San Pedro, en el trazado de las rutas de comunicación con Córdoba y Santiago del Estero y aún en la planificación de las campañas militares de finales del siglo XIX.

$<$ cazadores-recolectores $><$ cambio climático $><$ tierras bajas $><$ Santa Fe $>$

\begin{abstract}
This work is an attempt to relate movements of human population registered in the Chaco domain of the Santa Fe's Province, Argentina with the Holocen's climatic change and the use of water. This situation brought the occupation of alluvial belts as well as the sides of deflation depressions localized in paleoriverbeds; and seasonal movements as an adaptative strategy of the hunter-gatherers of the Esperanza's cultural entitie. Also water kept being important during the posthispanic times, even after horse adaptation by Chaco's groups, being a determinant factor to decide the localization of the San Pedro's jesuitic Reduction, the draft of routes that communicated with Córdoba and Santiago del Estero, and even in the planifitacion of militar compaigns at the end of de $19^{\text {th }}$ century.
\end{abstract}

$<$ hunter-gatherers $><$ climatic changes $><$ lowlands $><$ Santa Fe $>$ 